\title{
Noise attenuation varies by interactions of land cover and season in an urban/peri-urban landscape
}

\author{
Justin M. Gaudon ${ }^{1,2,3} \cdot$ Michael J. McTavish ${ }^{1}$. Jonas Hamberg ${ }^{1,2} \cdot$ Heather A. Cray ${ }^{2,4} \cdot$ Stephen D. Murphy ${ }^{2}$
}

Accepted: 6 December 2021 / Published online: 16 January 2022

(c) The Author(s), under exclusive licence to Springer Science+Business Media, LLC, part of Springer Nature 2021

\begin{abstract}
Anthropogenic noise is increasing worldwide because of growing human populations, transportation, and resource extraction. This excessive noise negatively impacts humans and wildlife. To mitigate noise pollution, the use of vegetation in urban planning is becoming increasingly common. However, noise attenuation can be influenced by poorly understood differences in land cover and seasonality that exist across complex urban and peri-urban environments. We compared the noise attenuation capacity of sites typifying dominant land covers in southern Ontario, Canada (forest, tallgrass prairie, and agriculture) across three seasons (summer, fall, and winter). We found that total noise attenuation was affected by a complex interaction of both site and season across low $(250 \mathrm{~Hz})$, $\operatorname{mid}(500 \mathrm{~Hz})$, and high $(1000 \mathrm{~Hz})$ frequency sound. Seasonal changes in vegetation density varied between sites and seemed to play only a partial role in total noise attenuation. While forest, trees, and shrubs continue to be effective for managing noise pollution, our results suggest that other types of land cover can also be useful (e.g., tallgrass prairie). With growing interest in the potential noise attenuating capabilities of vegetation, we recommend further consideration of the seasonal variation in attenuation that can occur across the diverse land covers of urban and peri-urban environments.
\end{abstract}

Keywords Ecosystem services $\cdot$ Noise pollution $\cdot$ Noise barriers $\cdot$ Soundscape ecology $\cdot$ Urban ecology

\section{Introduction}

Noise is unwanted, unpleasant, or disruptive sound. Global anthropogenic noise levels are rising due to increasing human populations, transportation, and resource extraction (Shannon et al. 2016). Anthropogenic noise is a form of

JMG and MJM co-first authors, alphabetical order.

Justin M. Gaudon

justin.gaudon@uwaterloo.ca

1 Institute of Forestry \& Conservation, John H. Daniels Faculty of Architecture, Landscape and Design, University of Toronto, 33 Willcocks Street, Toronto, ON M5S 3B3, Canada

2 School of Environment, Resources and Sustainability, University of Waterloo, 200 University Avenue West, Waterloo, ON N2L 3G1, Canada

3 rare Charitable Research Reserve, 1679 Blair Road, ON N3H 4R8 Cambridge, Canada

4 School for Resource and Environmental Studies, Dalhousie University, 6100 University Avenue, Halifax, NS B3H 4R2, Canada environmental change and pollution that negatively impacts both humans and wildlife (Kunc and Schmidt 2019). In humans, excessive noise is a leading environmental burden of disease (Hänninen et al. 2014), with both physiological (Babisch 2006; Haralabidis et al. 2008) and psychological health impacts (Michaud et al. 2008). In wildlife, noise pollution has deleterious effects in both terrestrial and aquatic ecosystems, altering vocalizations, local abundance, fitness, and community structure (Shannon et al. 2016; Kunc and Schmidt 2019). Impacts of noise pollution are expected to increase, particularly in urban and peri-urban areas exposed to high levels of road traffic noise (Morillas et al. 2018).

The detrimental impacts of noise pollution can be mitigated through vegetation, with growing awareness of the role of vegetation for noise control in mainstream urban planning (Morillas et al. 2018). While urban planning has focused primarily on planting vegetation or installing mechanical barriers to reduce noise pollution (Kalansuriya et al. 2009; Bashir et al. 2015), retaining large tracts of natural areas can also be useful to separate different zoning areas and may be preferred in large-scale applications where other barriers might be impractical or prohibitively expensive (Maleki and 
Hosseini 2011; Bashir et al. 2015). Conversely, the loss of existing vegetation can increase anthropogenic noise pollution and should be avoided to retain this valuable ecosystem service (Laverne and Kellogg 2019).

Vegetation attenuates sound through scattering (e.g., by stems and branches), absorption (e.g., by foliage), and destructive interference (e.g., resulting from interactions with the ground) (Fricke 1984). These mechanisms can be influenced by several factors including the frequency of the noise (Aylor 1972; Fricke 1984), the amount and type of vegetation (Martens 1981; Price et al. 1988), ground cover (Bashir et al. 2015), the spatial arrangement of vegetation (Van Renterghem et al. 2012), and weather parameters such as relative humidity (Fricke 1984). Vegetation most strongly attenuates high frequency sound (e.g., $\geq 1 \mathrm{kHz}$ ) through absorption by foliage (Aylor 1972; Bullen and Fricke 1982; Fricke 1984), while soft, porous ground with vegetation litter inputs and rooting is most important for attenuating low frequencies (e.g., $<250-500 \mathrm{~Hz}$ ) (Van Renterghem et al. 2012).

One of the least well documented factors that can affect noise attenuation by vegetation is seasonality. In temperate regions, deciduous vegetation undergoes dramatic changes in height, stem diameter, and foliage density, which can influence a plant's ability to attenuate noise (Price et al. 1988). Vegetation may also affect ground cover and destructive interference based on seasonal litter inputs and influence on snow cover. Additionally, human-altered landscapes with seasonal management may undergo drastic changes such as planting and harvesting crops or tilling an agricultural field (Aylor 1972; Bashir et al. 2015). Previous studies have generally compared vegetation between times of peak and reduced foliage (e.g., summer vs. fall or winter) and found reduced attenuation in seasons with low density vegetation (Aylor 1972; Price et al. 1988; Maleki and Hosseini 2011; Bashir et al. 2015). The number of studies investigating the seasonality of attenuation remains limited and has typically compared attenuation between only two seasons in forest (Aylor 1972; Price et al. 1988; Maleki and Hosseini 2011), urban parks (Tashakor and Chamani 2021), or agriculture (Bashir et al. 2015).

Land cover can also affect attenuation potential. Different species of vegetation have stems and foliage with differing morphologies, acoustic properties, and densities that can influence attenuation capacity (Price et al. 1988). Vegetation communities also differ in ground cover and soil properties (Van Renterghem et al. 2012), which are factors that may also vary seasonally. Historically, the sound attenuation literature has focused heavily on attenuation by trees and shrubby vegetation (e.g., Aylor 1972; Price et al. 1988; Maleki and Hosseini 2011) and the attenuation capacity of other vegetation communities such as grasslands (e.g., tallgrass prairie) remain less understood (Bashir et al. 2015).
Given the potential for noise attenuation by vegetation to differ substantially across the diverse types of land cover that exist in urban and peri-urban environments (Aylor 1972), it is important to better understand the factors that influence these differences. The purpose of this study was to compare the noise attenuation of three types of land cover (forest, tallgrass prairie, and agriculture) in an urban/peri-urban landscape in southern Ontario, Canada across three seasons (summer, fall, and winter).

\section{Methods}

We selected three study sites that were representative of three of the dominant land cover types at the rare Charitable Research Reserve (Cambridge, Ontario, Canada): forest, tallgrass prairie, and agricultural. At each site, a 50-m transect with seven random sampling points was established and sampled in the summer (27 June 2019), fall (21 October 2019), and winter (14 February 2019); due to the global COVID-19 pandemic, our planned spring sampling could not be completed. At each sampling point, a powered studio monitor speaker (Mackie CR3 $50 \mathrm{~W}$ 3") was used to produce constant tones for low dBA $(250 \mathrm{~Hz})$, mid dBA $(500 \mathrm{~Hz})$, and high dBA $(1000 \mathrm{~Hz})$ frequencies (Fricke 1984; Pal et al. 2000). Even source sound pressure level was maintained by using a consistent power supply to the speaker and consistent setting of the speaker output (90\% volume). Sound pressure level was measured using a sound level meter (REED ST-805), recording the average A-weighted sound pressure level (dBA, corresponding to the human perception of noise) observed during a minimum of $5 \mathrm{~s}$ of monitoring. The speaker and sound level meter were held at a distance of $5 \mathrm{~m}$ and pointed directly at each other at a constant height of $1 \mathrm{~m}$ above the ground. The $1 \mathrm{~m}$ height was chosen to capture seasonal variations in vegetation density at the three observation sites. Five $m$ has been identified as an ideal depth of vegetation for attenuating traffic noise (Ow and Ghosh 2017) and was chosen as a practical working distance for clearly discerning sound from the speaker source compared to background ambience and for making visual measurements of vegetation density (see below). We chose to sample on days that were characteristic of season in southern Ontario and measurements were taken only when extreme weather events (e.g., wind, precipitation) and obvious extraneous environmental noises (e.g., road and air traffic) were absent.

In addition to the seven main sound pressure level measurements per site, reference noise measurements were taken at the first, fourth, and seventh sampling points at each site at a distance of $1 \mathrm{~m}$ and averaged to account for variation in background noise between sites and over time. The main response variable calculated from each measurement was mean total sound attenuation (\% dBA) over $4 \mathrm{~m}$, measured as the percent 
difference in sound pressure level at $5 \mathrm{~m}$ relative to the mean $1 \mathrm{~m}$ reference value for each site. This method allowed for a standardized comparison between sites and sampling times (Pal et al. 2000) and helped mitigate potential minor fluctuations in background noise or sound pressure level at the speaker source. At the first, fourth, and seventh sampling points, we also took photos to descriptively characterize the vertical vegetation density at $1 \mathrm{~m}$ with ImageJ (Rasband 1997-2018). Images were cropped, the colour threshold was adjusted manually (by hue, saturation, brightness), and the vegetation density (\% cover) was calculated using the 'Analyze Particles' and 'Summarize' functions. The forest site was dominated by sugar maple, Acer saccharum Marshall (Sapindaceae), and American beech, Fagus grandifolia Ehrh. (Fagaceae). The tallgrass prairie was a mix of dense, $>1 \mathrm{~m}$ tall vegetation, typically grasses as well as forbs [i.e., Solidago spp. L. (Asteraceae), Aster spp. L. (Asteraceae)] all planted in 2010; the last prescribed burn was in 2015. The agricultural site was a $100 \%$ corn [Zea mays L. (Poaceae)] monoculture planted before summer sampling and harvested before winter sampling.

The effects of site (forest, tallgrass prairie, and agriculture) and season (summer, fall, and winter) on the total attenuation of each of the three frequencies $(250,500$, and $1000 \mathrm{~Hz}$ ) were assessed using mixed-effects ANOVAs; site and season were included as fixed factors and sample point as a random factor to account for repeated measures over time. As assumptions of sphericity are often violated during the analysis of repeated measures data, we applied the Huynh-Feldt degrees of correction $\left(\varepsilon_{\mathrm{HF}}\right)$ as departures from sphericity were generally minimal (i.e., $\varepsilon>0.75$ ) (Quinn and Keough 2002). For significant interactions of site and season, we assessed the simple main effects of season by site using one-way ANOVA with repeated measures, and the simple main effects of site by season using either a one-way ANOVA or Welch's ANOVA for heteroscedastic data (Welch 1951). Omega squared $\left(\omega^{2}\right)$ or partial omega squared $\left(\omega_{\mathrm{p}}{ }^{2}\right)$ are given as an effect size for all statistically significant single- and multi-factor tests respectively (Maxwell and Delaney 2004). Mixed-effects ANOVAs with Huynh-Feldt corrections were conducted in the Real Statistics Resource Pack 6.2 (Zaiontz 2018). All other analyses were performed in $\mathrm{R}$ version 3.6.1 ( $\mathrm{R}$ Core Team 2019) using the 'userfriendlyscience' package (v.0.7.2, Peters 2018). Graphics were produced in Microsoft Excel. We tested assumptions of residual normality and equal variance using graphical examination and Levene's Test respectively (Henderson 2006; Gastwirth et al. 2009). All statistical tests were conducted at $\alpha=0.05$.

\section{Results}

Mean total sound attenuation across $4 \mathrm{~m}$ ranged from $9.5 \%$ (mid frequency, tallgrass prairie, winter) to $24.6 \%$ (low frequency, tallgrass prairie, summer). Overall, total noise attenuation was affected by an interaction of both site and season across all measured frequencies, including low (Mixed ANOVA, $\mathrm{F}_{4.0,36.0}=2.79, p=0.0405, \varepsilon_{\mathrm{HF}}=1.00$, $\left.\omega_{\mathrm{p}}{ }^{2}=0.13\right)$, mid $\left(\mathrm{F}_{3.4,30.6}=3.57, p=0.0212, \varepsilon_{\mathrm{HF}}=0.85\right.$, $\left.\omega_{\mathrm{p}}{ }^{2}=0.15\right)$, and high frequencies $\left(\mathrm{F}_{2.9,26.5}=3.02\right.$, $\left.p=0.0485, \varepsilon_{\mathrm{HF}}=0.74, \omega_{\mathrm{p}}{ }^{2}=0.13\right)$. The simple main effects of site for each season and of season for each site are summarized in Table 1 and Fig. 1.

Each of the three sites offered the highest total noise attenuation (or had comparable attenuation to one or both other land cover types) in more than one unique combination of season and frequency (Table 2). The forest, tallgrass prairie, and agricultural sites offered the highest attenuation in eight, seven, and five respectively of the nine possible combinations of frequency and season.

Descriptively, vegetation density differed between sites and seasons (Figs. 2 and 3). The agricultural site varied the most, with no vegetation at a $1 \mathrm{~m}$ height in the summer (before corn had grown) or winter (after corn had been harvested), but high cover $(93 \%)$ in the fall (prior to harvest). The tallgrass prairie had generally lower vegetation density overall (2-24\%), increasing over the summer to the fall growing season and then decreasing in the winter. The forest had moderate vegetation density that was highest in the summer (44\%) and decreased in the fall with the loss of foliage and remaining relatively consistent into the winter (15-17\%).

\section{Discussion}

\section{Noise attenuation of different frequencies}

Some of the greatest interest in urban planning is focused on mitigating low frequency noise that is often produced by vehicles and machinery (Van Renterghem et al. 2012) and is thought to be attenuated primarily by interactions with soft ground rather than by vegetation (Fricke 1984). Overall, the agricultural site provided the lowest attenuation of low frequencies (17-19\%), with the poorest performance in the early summer (Fig. 1), possibly due to the acoustically hard, exposed soil that existed prior to corn planting (Bashir et al. 2015). The forest and tallgrass prairie sites generally provided the highest attenuation (17-25\%) with no detectable seasonal effects (Fig. 1). Both the forest and tallgrass prairie sites had substantial year-round litter layers compared to the relatively exposed soils of the agricultural site, which likely contributed to their overall superior sound attenuation of low frequencies and lack of seasonal variation (Van Renterghem et al. 2012).

Although vegetation and associated ground cover are expected to have the strongest attenuating impacts on low 
Table 1 Summary of the simple main effects of site (forest, tallgrass prairie, agriculture) by season and season by site on the total sound attenuation of (a) low, (b) mid, and (c) high frequencies $(n=7$ for each unique combination of site and season). Simple main effects of site by season report results of one-way ANOVA or Welch's ANOVA for heteroscedastic data. Simple main effects of season by site report results of one-way repeated measures ANOVA with Huynh-Feldt corrections $\left(\varepsilon_{\mathrm{HF}}\right)$. Significant $p$-values are in bold (a) LOW

\begin{tabular}{|c|c|c|c|c|c|}
\hline \multicolumn{6}{|c|}{ Simple Main Effects: Site by Season } \\
\hline Factor Level & Test & Test-Statistic & $p$-value & $\varepsilon_{\mathrm{HF}}$ & $\omega^{2}$ \\
\hline Summer & Welch's ANOVA & 24.81 & $<0.001$ & - & 0.31 \\
\hline Fall & Welch's ANOVA & 31.78 & $<0.001$ & - & 0.23 \\
\hline Winter & One-way ANOVA & 5.51 & 0.014 & - & 0.30 \\
\hline \multicolumn{6}{|c|}{ Simple Main Effects: Season by Site } \\
\hline Factor Level & Test & Test-Statistic & $p$-value & $\varepsilon_{\mathrm{HF}}$ & $\omega^{2}$ \\
\hline Agriculture & RM ANOVA & 6.60 & 0.012 & 1.00 & 0.37 \\
\hline Tallgrass Prairie & RM ANOVA & 3.13 & 0.916 & 0.86 & - \\
\hline Forest & RM ANOVA & 1.81 & 0.206 & 1.00 & - \\
\hline \multicolumn{6}{|l|}{ (b) MID } \\
\hline \multicolumn{6}{|c|}{ Simple Main Effects: Site by Season } \\
\hline Factor Level & Test & Test-Statistic & $p$-value & $\varepsilon_{\mathrm{HF}}$ & $\omega^{2}$ \\
\hline Summer & One-way ANOVA & 0.45 & 0.643 & - & - \\
\hline Fall & One-way ANOVA & 28.71 & $<0.001$ & - & 0.73 \\
\hline Winter & Welch's ANOVA & 52.67 & $<0.001$ & - & 0.61 \\
\hline \multicolumn{6}{|c|}{ Simple Main Effects: Season by Site } \\
\hline Factor Level & Test & Test-Statistic & $p$-value & $\varepsilon_{\mathrm{HF}}$ & $\omega^{2}$ \\
\hline Agriculture & RM ANOVA & 19.49 & $<0.001$ & 1.00 & 0.62 \\
\hline Tallgrass Prairie & RM ANOVA & 26.43 & $<0.001$ & 0.68 & 0.70 \\
\hline Forest & RM ANOVA & 7.92 & 0.006 & 1.00 & 0.41 \\
\hline \multicolumn{6}{|c|}{ (c) HIGH } \\
\hline \multicolumn{6}{|c|}{ Simple Main Effects: Site by Season } \\
\hline Factor Level & Test & Test-Statistic & $p$-value & $\varepsilon_{\mathrm{HF}}$ & $\omega^{2}$ \\
\hline Summer & One-way ANOVA & 5.08 & 0.018 & - & 0.28 \\
\hline Fall & One-way ANOVA & 3.88 & 0.040 & - & 0.22 \\
\hline Winter & One-way ANOVA & 1.34 & 0.286 & - & - \\
\hline \multicolumn{6}{|c|}{ Simple Main Effects: Season by Site } \\
\hline Factor Level & Test & Test-Statistic & $p$-value & $\varepsilon_{\mathrm{HF}}$ & $\omega^{2}$ \\
\hline Agriculture & RM ANOVA & 6.84 & 0.011 & 0.97 & 0.27 \\
\hline Tallgrass Prairie & RM ANOVA & 1.25 & 0.309 & 0.54 & - \\
\hline Forest & RM ANOVA & 3.30 & 0.072 & 1.00 & - \\
\hline
\end{tabular}

and high frequency sound (Aylor 1972; Fricke 1984), some of the largest seasonal and site effect sizes were observed for mid frequency noise $\left(\omega^{2}: 0.41-0.73\right)$ (Table 1$)$. Attenuation of mid frequencies also had the most consistent seasonal patterns across sites, generally decreasing from summer to fall to winter (Fig. 1). Attenuation in the agricultural site was also surprisingly high, with no site differences in summer but providing the most attenuation in fall (possibly from the presence of high density, sound-scattering corn stems) (Fig. 2) and comparable attenuation to forest in the winter (Fig. 1). Mechanisms that attenuate mid-frequencies are more cryptic but it may be from scattering by stems and branches (Fricke 1984). Given the variable seasonality of vegetation density across sites (Fig. 2), the overarching seasonal pattern of mid frequency attenuation may also be driven by a shared meteorological variable such as relative humidity (Fricke 1984) or snow cover, both of which require additional study.
High frequency sound is thought to be most strongly attenuated by absorption by foliage (Aylor 1972) and was expected to have strong seasonal trends and differences between sites with differing vegetation. Overall, however, the simple main effect sizes of both season and site were only moderate $\left(\omega^{2}: 0.22-0.28\right)$ (Table 1$)$. High frequency noise showed similar patterns to low frequency, with generally the least attenuation by the agricultural site (12-16\%) that was lowest in the summer, again likely due to the complete absence of vegetation prior to planting (Fig. 2). The highest attenuation mostly came from forest and tallgrass prairie (15-21\%) (Fig. 1), where tree and grass standing foliage may offer greater absorption compared to the corn biomass only present during a part of the year and comprising relatively hard stems (Price et al. 1988). Foliage absorption did not seem to exclusively dominate high frequency attenuation, however, as forest 

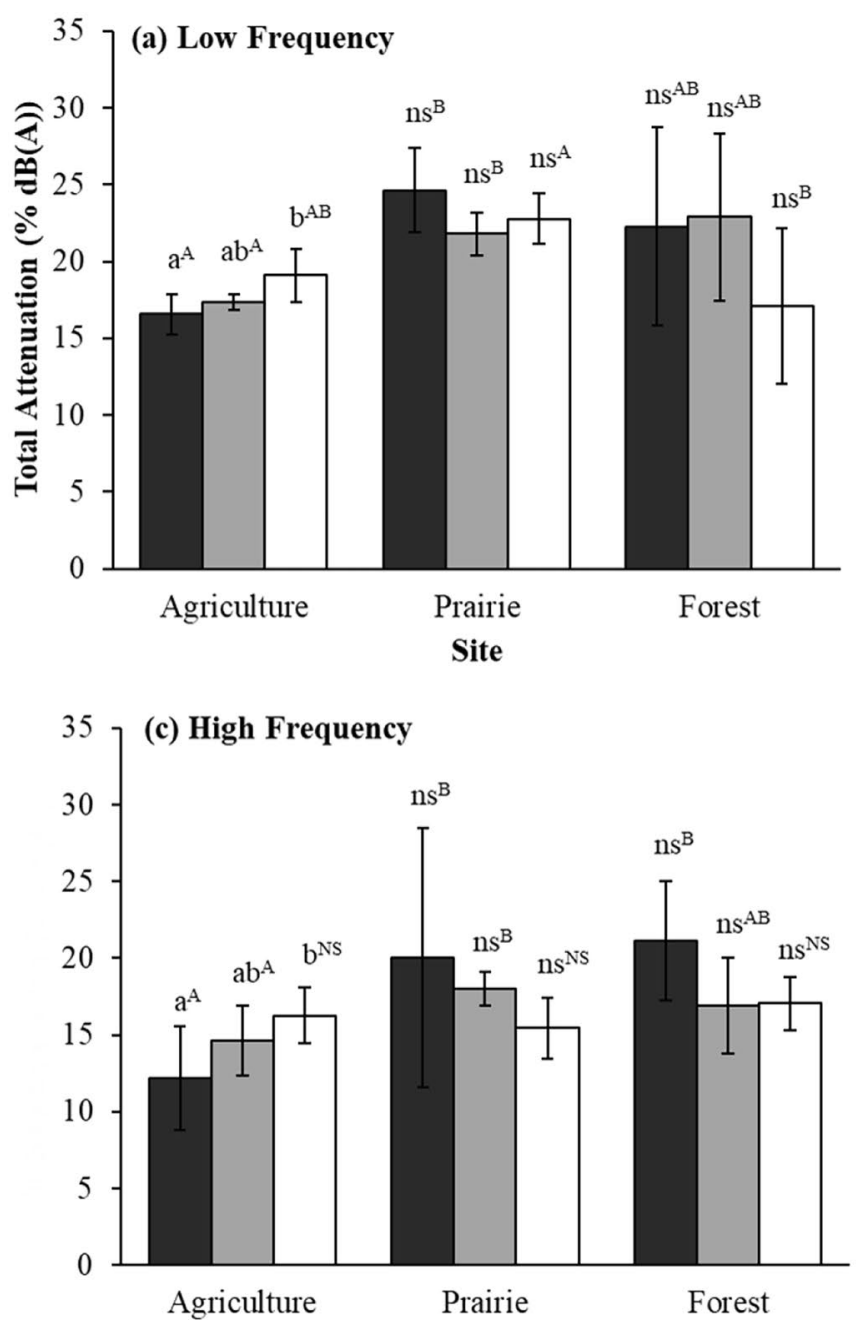

Fig. 1 Bar charts depicting the mean total sound attenuation of (a) low, (b) mid, and (c) high frequencies at different sites (agriculture, tallgrass prairie, forest) and seasons (summer, fall, winter) $(n=7$ samples per unique treatment combination). Error bars show \pm 1 standard deviation. Letters denote post-hoc groupings from Tukey's HSD

and tallgrass prairie had no strong seasonal patterns in attenuating high frequency noise (Fig. 1), despite seasonal differences in vegetation density (Fig. 2). Notably, all sites attenuated high frequency sound comparably in the winter

Table 2 Summary of sites with maximum mean total noise attenuation (\%) for each frequency and season. Maximum mean attenuation was chosen based on post-hoc groups in Fig. 1. For comparisons with

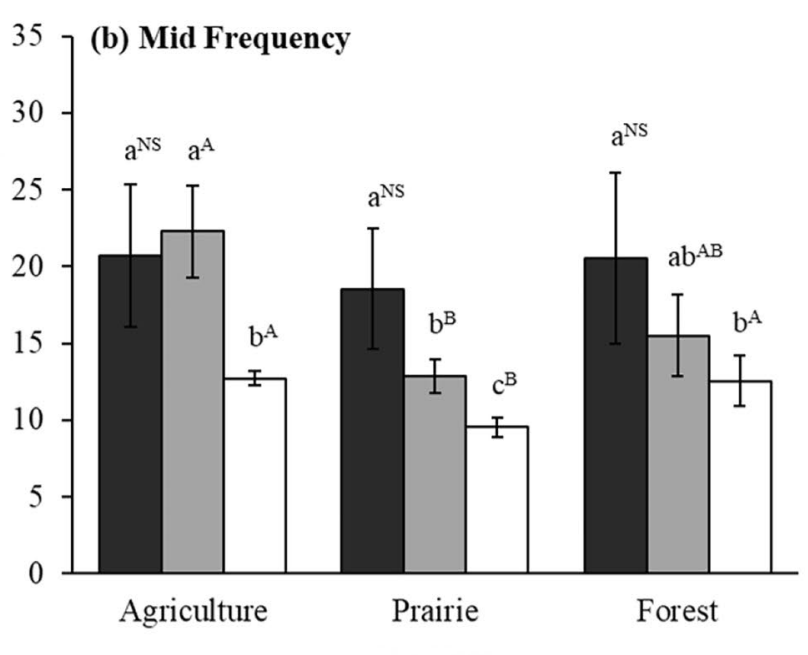

๑Summer $\square$ Fall $\square$ Winter

\begin{tabular}{llll}
\hline & Season & & \\
\cline { 2 - 4 } Frequency & Summer & Fall & Winter \\
\hline Low $(250 \mathrm{~Hz})$ & Tallgrass Prairie (25\%)/ & Forest (23\%)/ & Tallgrass Prairie (23\%)/ \\
& Forest (22\%) & Tallgrass Prairie (22\%) & Agriculture (19\%) \\
$\operatorname{Mid}(500 \mathrm{~Hz})$ & All (19-21\%) & Agriculture (22\%)/ & Forest (12\%) \\
High $(1000 \mathrm{~Hz})$ & & Forest (16\%) & All (15-17\%) \\
& Forest (21\%)/ & Tallgrass Prairie (18\%)/ & \\
\hline
\end{tabular}




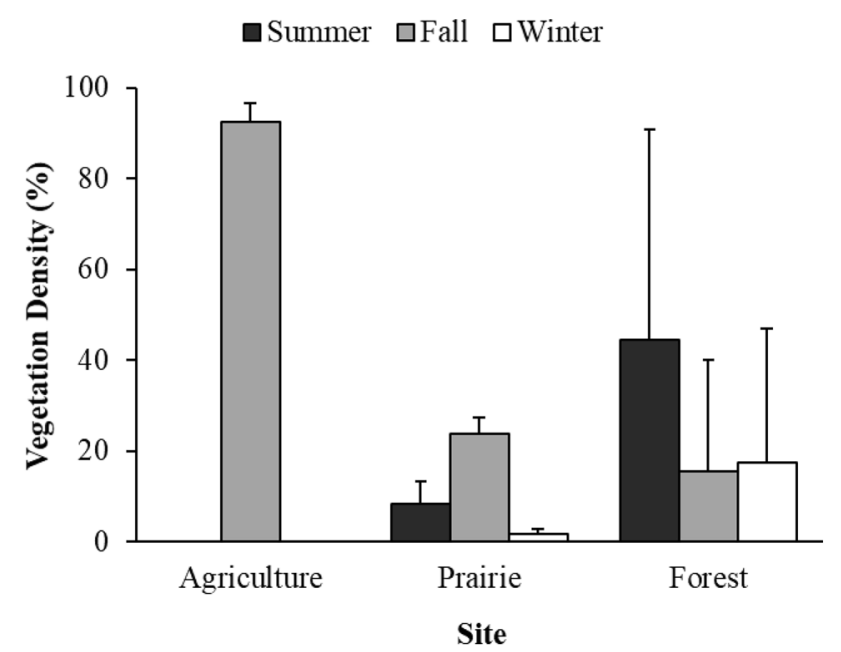

Fig. 2 Bar chart of vegetation density (\% cover) at $1 \mathrm{~m}$ height of three different land covers (agriculture, tallgrass prairie, forest) in three seasons (summer, fall, winter) ( $n=3$ measurements per unique treatment combination). Error bars show \pm 1 standard deviation

\section{Synthesis: complex interactions, looking beyond vegetation density, and acknowledging the attenuation potential of different land covers}

Overall, our results can be synthesized into three general observations. First, noise attenuation can be influenced by a complex interaction of several factors including site, seasonality, and the frequency of the noise. In particular, our study demonstrates not only how attenuation can change seasonally

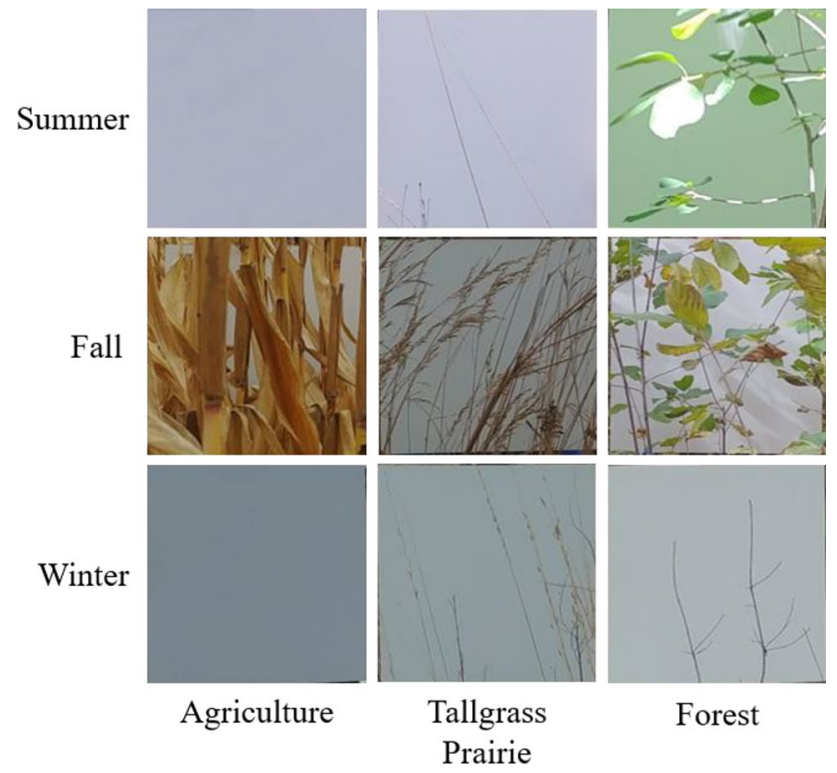

Fig. 3 Vegetation density cover photographs (prior to cropping and processing) showing characteristic vegetation at each of the three sites (agriculture, tallgrass prairie, forest) through the three sampling seasons (summer, fall, winter)
(Aylor 1972; Price et al. 1988; Maleki and Hosseini 2011; Bashir et al. 2015), but also how these changes differ between vegetation communities. Of the three sites we sampled, the agricultural site had the most seasonally variable attenuation, generally increasing over summer-fall-winter for low and high frequencies and decreasing for mid frequencies. In contrast, the forest and tallgrass prairie sites had no seasonal differences in the attenuation of low or high frequencies but showed relatively strong seasonal decreases in attenuation of mid frequencies (Fig. 1).

While the density of foliage and stems is not the only factor influencing attenuation (see the second observation below), it likely plays a key role (Aylor 1972) and changed variably between the sites and seasons: all sites differed in when they experienced their peak vegetation density (agriculture and tallgrass prairie in fall, forest in summer) and the highest vegetation density in a given season occurred at different sites (forest for summer and winter, agriculture for fall) (Fig. 2). Our results suggest that it would be oversimplistic to assume that attenuation would automatically decrease in cooler, non-peak growing seasons without also considering the type of land cover.

Second, while the seasonal changes in vegetation density described above likely affected total attenuation through absorption by foliage and scattering by stems and branches (Fricke 1984), vegetation density itself cannot fully explain the attenuation effect. Although treated descriptively in this study, the patterns of vegetation density as compared between sites and seasons (Fig. 2) do not neatly correspond with the patterns of total attenuation observed in the field (Fig. 1). Similarly, while tallgrass prairie had the highest (or shared the highest) attenuation capacity for many of the frequencies and seasons overall (Table 2), it had lower overall vegetation density (2-24\%) compared to agriculture (0-93\%) or forest (15-44\%) (Fig. 2). While higher vegetation density tends to increase attenuation, this response is non-linear, with diminishing returns in attenuation for increasing density (Aylor 1972). Other likely influential mechanisms include the spatial arrangement of vegetation (Van Renterghem et al. 2012) and the acoustic hardness of the ground due to snow cover and litter inputs (Aylor 1972; Bashir et al. 2015). Both mechanisms are likely to further differ with land cover and seasonality and should be the focus of future investigations.

Third, while there has been a strong focus on the noise attenuating potential of forests or trees and shrubs in the acoustic and environmental literature and urban planning (e.g., Aylor 1972; Price et al. 1988; Maleki and Hosseini 2011), our results suggest that the attenuation potential of other land cover types should not be overlooked. Forest did provide the highest (or shared the highest) attenuation capacity for eight of the nine combinations of season and frequency; however, tallgrass prairie and agriculture provided 
the highest attenuation in seven and five of the scenarios respectively (Table 2), and agriculture provided the best overall attenuation for mid frequency noise across the seasons (Fig. 1). While tallgrass prairie had the lowest observed attenuation (10\% of mid frequency in the winter), it also had the highest observed attenuation observed in this study (25\% of low frequency in the summer). Overall, while forests are clearly beneficial for noise attenuation and trees and shrubs remain useful as sound barriers for urban planning (Laverne and Kellogg 2019), these results suggest that other land cover types such as tallgrass prairie or other grasslands - or other vegetation types not explored in this study such as hedges (Biocca et al. 2019) - can also be useful in various applications such as roadsides (Bashir et al. 2015) or large-scale zoning (Maleki and Hosseini 2011).

\section{Implications for future research}

This was a relatively small-scale study intended as a preliminary investigation of interactive effects of site and seasonality on noise attenuation. As a result, the scope was limited to three field sites, with each representing a different land cover type. While we chose sites that we believe to be representative of their vegetation communities (i.e., corn monoculture, restored tallgrass prairie, and temperate forest), we recommend caution in broadly generalizing the results beyond these specific communities. Given our preliminary findings, we encourage further study using multiple sites to represent each vegetation community. As a pilot study, we suggest that future research expand on the monitoring equipment and approaches used here. Given the potential for variation in attenuation with both vertical position and distance between a source and receiver (Bashir et al. 2015), we recommend more detailed monitoring of this phenomenon using multiple vertical and horizontal measurement configurations. Future studies may also consider both pure tones of varying frequency and more complex sounds of interest such as air or land traffic noise; studies investigating more complex sounds will benefit from additional spectral analysis of attenuation effects at different frequencies (e.g., Bashir et al. 2015). Overall, our results highlight the importance of assessing attenuation across multiple points in the year; while we were unable to complete our planned spring season sampling due to the global COVID-19 pandemic, we recommend that future studies extend their sampling beyond only local maxima and minima in vegetation growth (e.g., summer and winter in temperate Ontario) to include transition seasons (e.g., fall, spring).

Noise attenuation of each of the three tested frequencies varied by interactions of site and season. In contrast with the few existing studies of seasonality that observed reduced attenuation in the fall or winter compared to spring or summer, presumed to result from reduced vegetation density
(Aylor 1972; Price et al. 1988; Maleki and Hosseini 2011; Bashir et al. 2015), our study examined a greater range of sites over several seasons and found complex interactions of noise frequency, site, and season. These interactions pose important questions about the overall year-round attenuation capacities of different types of land cover and the potential seasonal trade-offs in planting different types of vegetation for attenuation (e.g., deciduous vs. coniferous trees) (Tashakor and Chamani 2021). As greater attention is paid to the noise attenuating benefits of vegetation in urban planning - whether the vegetation is already present in the landscape and retained or introduced intentionally - we suggest further consideration and study of the seasonal variation in attenuation that can occur across the diverse land covers that comprise urban and peri-urban environments.

Acknowledgements Field work was completed on the treaty and ancestral lands of the Onkwehon:we Peoples of Six Nations of the Grand River and the Anishinaabe Peoples of the Mississaugas of the New Credit First Nation. We thank the rare Charitable Research Reserve for site access and financial support.

Author contribution JH and HAC conceived the experiment, all authors designed and conducted the experiment, MJM and JMG processed and analyzed the data, and all authors contributed to writing the manuscript.

Funding Research was supported by the rare Charitable Research Reserve.

\section{Declarations}

Conflict of interest The authors declare that they have no conflict of interest.

\section{References}

Aylor D (1972) Noise reduction by vegetation and ground. J Acoust Soc Am 51:197-205. https://doi.org/10.1121/1.1912830

Babisch W (2006) Transportation noise and cardiovascular risk: Updated review and synthesis of epidemiological studies indicate that the evidence has increased. Noise Health 8:1. https://doi.org/ 10.4103/1463-1741.32464

Bashir I, Taherzadeh S, Shin H-C, Attenborough K (2015) Sound propagation over soft ground without and with crops and potential for surface transport noise attenuation. J Acoust Soc Am 137:154164. https://doi.org/10.1121/1.4904502

Biocca M, Gallo P, Loreto GD et al (2019) Noise attenuation provided by hedges. J Agric Eng 50:113-119. https://doi.org/10.4081/jae. 2019.889

Bullen R, Fricke F (1982) Sound propagation through vegetation. J Sound Vib 80:11-23. https://doi.org/10.1016/0022-460X(82) 90387-X

Fricke F (1984) Sound attenuation in forests. J Sound Vib 92:149-158. https://doi.org/10.1016/0022-460X(84)90380-8

Gastwirth JL, Gel YR, Miao W (2009) The impact of Levene's test of equality of variances on statistical theory and practice. Stat Sci $24: 343-360$ 
Hänninen O, Knol AB, Matti J et al (2014) Environmental burden of disease in Europe: Assessing nine risk factors in six countries. Environ Health Persp 122:439-446. https://doi.org/10.1289/ehp. 1206154

Haralabidis AS, Dimakopoulou K, Vigna-Taglianti F et al (2008) Acute effects of night-time noise exposure on blood pressure in populations living near airports. Eur Heart J 29:658-664. https://doi.org/ 10.1093/eurheartj/ehn013

Henderson AR (2006) Testing experimental data for univariate normality. Clin Chim Acta 366:112-129. https://doi.org/10.1016/j. cca.2005.11.007

Kalansuriya CM, Pannila AS, Sonnadara DUJ (2009) Effect of roadside vegetation on the reduction of traffic noise levels. Proceedings of the Technical Sessions, Institute of Physics Sri Lanka 25:6

Kunc HP, Schmidt R (2019) The effects of anthropogenic noise on animals: a meta-analysis. Biol Letters 15:20190649. https://doi. org/10.1098/rsbl.2019.0649

Laverne RJ, Kellogg WA (2019) Loss of urban forest canopy and the effects on neighborhood soundscapes. Urban Ecosyst 22:249-270. https://doi.org/10.1007/s11252-018-0820-4

Maleki K, Hosseini SM (2011) Investigation of the effects of leaves, branches and canopies of trees on noise pollution reduction. Ann Environ Sci 5:13-21

Martens MJM (1981) Noise abatement in plant monocultures and plant communities. Appl Acoust 14:167-189. https://doi.org/10.1016/ 0003-682X(81)90029-3

Maxwell SE, Delaney HD (2004) Designing experiments and analyzing data: a model comparison perspective, 2 nd edn. Lawrence Erlbaum Associates, Mahwah, New Jersey

Michaud DS, Keith SE, McMurchy D (2008) Annoyance and disturbance of daily activities from road traffic noise in Canada. J Acoust Soc Am 123:784-792. https://doi.org/10.1121/1.2821984

Morillas JMB, Gozalo GR, González DM et al (2018) Noise pollution and urban planning. Curr Pollution Rep 4:208-219. https://doi. org/10.1007/s40726-018-0095-7
Ow LF, Ghosh S (2017) Urban cities and road traffic noise: Reduction through vegetation. Appl Acoust 120:15-20. https://doi.org/10. 1016/j.apacoust.2017.01.007

Pal AK, Kumar V, Saxena NC (2000) Noise attenuation by green belts. J Sound Vib 234:149-165. https://doi.org/10.1006/jsvi.2000.2863

Peters G (2018) userfriendlyscience: Quantitative analysis made accessible. http://doi.org/10.17605/osf.io/txequ

Price MA, Attenborough K, Heap NW (1988) Sound attenuation through trees: Measurements and models. J Acoust Soc Am 84:1836-1844. https://doi.org/10.1121/1.397150

Quinn GP, Keough MJ (2002) Experimental design and data analysis for biologists, 1st edn. Cambridge University Press, New York

R Core Team (2019) R: A language and environment for statistical computing. R Foundation for Statistical Computing, Vienna, Austria

Rasband WS (1997-2018) ImageJ. U.S. National Institutes of Health. Bethesda, Maryland, USA, https://imagej.nih.gov/ij/

Shannon G, McKenna MF, Angeloni LM et al (2016) A synthesis of two decades of research documenting the effects of noise on wildlife. Biol Rev 91:982-1005. https://doi.org/10.1111/brv.12207

Tashakor S, Chamani A (2021) Temporal variability of noise pollution attenuation by vegetation in urban parks. Environ Sci Pollut Res 28:23143-23151. https://doi.org/10.1007/s11356-021-12355-5

Van Renterghem T, Botteldooren D, Verheyen K (2012) Road traffic noise shielding by vegetation belts of limited depth. J Sound Vib 331:2404-2425. https://doi.org/10.1016/j.jsv.2012.01.006

Welch BL (1951) On the comparison of several mean values: An alternative approach. Biometrika 38:330-336. https://doi.org/10.1093/ biomet/38.3-4.330

Zaiontz C (2018) Real statistics using excel. Version 5.6. URL: www. real-statistics.com 